DOI: $10.14451 / 2.122 .34$

\title{
ИСПОЛЬЗОВАНИЕ ИНФОРМАЦИОННЫХ СИСТЕМ РАСПРЕДЕЛЕННОГО РЕЕСТРА ДЛЯ ПОВЫШЕНИЯ ЦЕННОСТИ УПРАВЛЕНИИ ОРГАНИЗАЦИЕЙ ЗДРАВООХРАНЕНИЯ
}

\author{
(c) 2018 Гуськова Марина Федоровна \\ доктор экономических наук, профессор кафедры “Менеджмент качества” \\ Российский университет транспорта (РУТ (МИИТ)) \\ 127994, г. Москва, ул. Образцова, д. 9, стр. 9 \\ (C) 2018 Богачев Денис Евгеньевич \\ кандидат экономических наук, доцент кафедры «Экономическая теория»
}

Московский государственный медико-стоматологический университет имени А.И. Евдокимова 127473, г. Москва, ул. Делегатская, д. 20, стр. 1

\section{(c) 2018 Кутеева Марина Вительевна}

кандидат экономических наук, доцент кафедры «Экономическая теория»

Московский государственный медико-стоматологический университет имени А.И. Евдокимова 127473, г. Москва, ул. Делегатская, д. 20, стр. 1

В отличии от принятия решения в рамках стандартной сети клиент - сервис в организации здравоохранения, которая предполагает централизацию информации на основе которой формируется решение, сеть блокчейн (одноранговая децентрализованная сеть) дает возможность избежать влияния субъективных факторов, используя только одновременную валидацию и верификацию каждого элемента системы распределенного реестра. Что позволит повысить эффективность работы врачей в результате освобождения рабочего времени.

Ключевые слова: системы распределенного реестра, ценность, разделение труда, принятие решений, валидация, сертификация, цифровизация.

Руководство страны взяло курс на цифровизацию экономики, что предполагает новую основу для развития всех сфер деятельности экономики, в том числе и системы государственного управления, частного бизнеса и социальной сферы, обеспечивающую укрепление национальной безопасности и независимости России, а также обеспечение конкурентной среды отечественных компаний [1].

Одной из важнейших и сложнейших для разрешения проблем управления организацией - это трансакционные издержки поиска и обеспечения достоверности информации при принятии эффективных управленческих решений [2].

Система управления организацией здравоохранения сложна еще и тем, что она направлена на обеспечение важнейшей потребности населения - здоровья граждан России. Поэтому нарушение процесса принятия решения при недостоверности информации в любом структурном подразделении организации здравоохранения может иметь негативные последствия для здоровья и жизни пациентов, особенно при необходимости принятия срочных решений.

Достижения результата по указанным 12 направлениям возможно только при обеспечении высокого качества оказания медицинских услуг. В нашей стране существует разветвленная и многогранная структура Стандартов качества в здравоохранении, коррелирующих с международными и национальными, а также со стандартами ИСО. Лечебные организации проходят сложную процедуру сертификации интегрированных систем менеджмента качества по ИСО и по отраслевым стандартам.

Однако не все руководящие работники и исполнители понимают какие неограниченные и конкретные возможности обеспечения качества медицинских услуг предоставляют выстроенные системы менеджмента качества.

Последнее время в научных журналах и в периодических изданиях широко используется принцип - следование лучшим практикам. Достижения конкретных учреждений здравоохранения по всей стране становятся доступными и обсуждаемыми. Это замечательная возможность узнать новые методы и подумать о воз- 
можности их внедрения в своей организации.

Был проведен анализ множества таких практик по следующим признакам, характеризующим системность нововведений:

- взаимоувязанность мероприятий;

- причинно-следственные связи улучшения критериев качества;

- процессный или поэлементный подход;

- экономия или эффективность.

В результате было выявлено, что, однозначно, эти практики достигли поставленной задачи и повысили удовлетворенность потребителей, однако, улучшались лишь некоторые направления деятельности и некоторые критерии качества. Чаше всего повышалась результативность нескольких процессов, таких как: комфортность условий получения медпомощи, оптимизация процесса диспансеризации, логистика анализов и все они сопровождаются новыми информационными технологиями с использованием современных программных продуктов. И, как вы видите - это процессы обеспечения качества услуг, которые являются декомпозиционными от основных бизнес-процессов организации здравоохранения. Одними из важных результатов представлены экономия ресурсов и рабочего времени.

Система менеджмента качества организации, в том числе и в здравоохранении, построена по принципу процессного подхода, а именно: есть основной бизнес-процесс оказания медицинских услуг, который состоит из системы взаимоувязанных процессов различных уровней декомпозиции, каждый из которых раскрывает и уточняет этапы декомпозируемого процесса. Например: процесс выдачи карточки пациента. У этого процесса есть вход (ресурс) - это карточка. А карточка - она является результатом другого процесса - процесса заполнения и наполнения карточки, которые связаны с процессами осмотра, забора анализов и т.д. То есть каждый процесс производит ценность, которая используется для производства услуги более сложной, создающей дополнительную ценность - оказания услуги здравоохранительной. Оказание медицинских услуг является одним из самых регламентированных видов деятельности. При этом каждый процесс обеспечивается информацией, которая хранится в соответствующей базе данных.

Как известно, разделение труда - источник повышения качества продукции. Процессный подход позволяет: анализировать, идентифицировать и непрерывно удовлетворять требования потребителя; классифицировать процессы с точки зрения прироста ценности, создаваемой каждым процессом; повышать результативность действия процессов; проводить их улучшение процессы используя оценку данных и информации.

Ресурсы не должны экономиться. Они должны быть ценными, или как форма проявления теории ценности для уровня хозяйствования «организация», эффективными:

Во-первых - разделение труда. Уже говорилось, что есть основные процесса, а есть процессы обеспечивающие. Основные процессы должны обеспечивать непосредственно медицинский персонал, а обеспечивающими процессами - специалисты из других профессий. Ведь мы не предполагаем, что машинист поезда будет заполнять базу данных. Но считаем, что высококвалифицированный врач должен ее заполнять. И экономия времени в результате лучших практик касается именно медицинского персонала.

Во-вторых - процессный подход. Управление бизнес-процессами организации - это профессиональные компетенции менеджеров. Именно эти специалисты могут правильно установить взаимосвязь и последовательность задач в системе оказания медицинских услуг. Подчеркиваю - установить взаимосвязь и последовательность! Это необходимо для построения основного бизнес-процесса и его декомпозиции. Задачи формулируют специалисты - медики. Регламенты разрабатывают также медики.

В-третьих - ресурсы всегда ограничены. Для эффективного использования всех (подчеркиваю) ресурсов все процессы должны быть взаимоувязаны и точно настроены. Только в этом случае возможно полное внедрение «Бережливого производства» во всей организации. И это уже входит в профессиональные компетенции системных администраторов и менеджеров низшего звена.

В случае реализации данных трех положений, на мой взгляд, можно говорить о следующем этапе не только повышения качества услуг, а всей ценности - величины полезности медицинской услуги на единицу стоимости.

Менеджмент бизнес-процессов - очень трудоемкое и многозадачное дело. Однако есть явные возможности упростить процедуру принятия управленческих решений, но при условии 
выполнения предыдущих трех тезисов.

В статьях российских ученых об использовании систем распределенного реестра (блокчейн) предлагаются различные направления его использования:

- в направлении задачи формирования системы для хранения информации о пациентах и предоставлении простого доступа к ней всех участников процесса предоставления услуг медицинскими учреждениями. Сейчас данные хранятся в рамках одного медицинского учреждения, а блокчейн может позволить аккумулировать информацию за все этапы жизни пациента и обеспечить доступ к ней при необходимости [3].

- создание базы данных «Здоровье России», предполагает аккумулирование медицинских знаний, значения мониторинга показателей здоровья населения и показателей качества окружающей среды. Применение базы данных позволит обучать население и предоставлять удаленные консультации по лечению. Для обеспечения надежной защиты личных данных и во избежание нежелательного воздействия с целью искажения данных и предоставления их населению требуется применение технологии блокчейн, краудсо́рсинга и Wiki. На текущем этапе развития IT-технологий уже есть и развиваются механизмы, позволяющие решатьтакие проблемы, как, например, технологии Wiki, краудсорсинга иблокчейн [4].

Предлагается:

1) на основе концепции и математического обеспечения Wiki, создать базу данных (знаний) по вопросам здоровья населения, состоянияо-

\section{Стандартная сеть клиент-сервер}

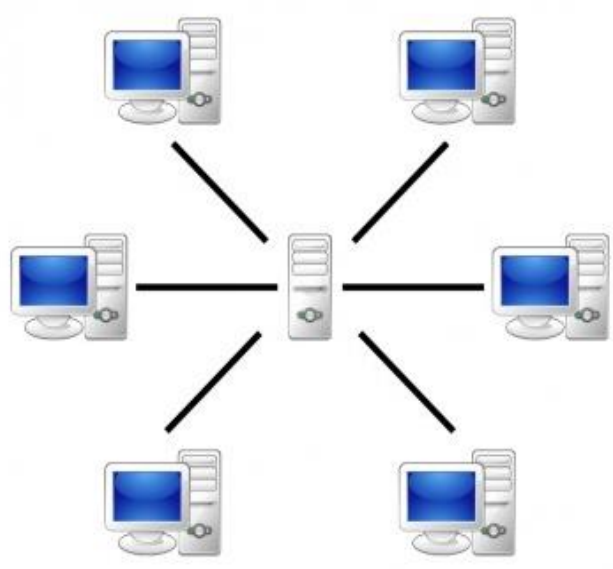

кружающей среды, качества продуктов питания и других товаров, влияющих на здоровье;

2) создать специальную социальную сеть, объединяющую владельцев специализированных гаджетов, волонтеров по сбору информации, представителей учреждений здравоохранения, оздоровительных и спортивных центров, учреждений по мониторингу окружающей среды и всех заинтересованных лиц. [5]

Система распределенного реестра предполагает согласование любого решения на основе валидации.

В отличии от принятия решения в рамках стандартной сети клиент - сервис в организации здравоохранения, которая предполагает централизацию информации, на основе которой формируется решение, сеть блокчейн (одноранговая децентрализованная сеть) дает возможность избежать влияния субъективных факторов, используя только одновременную валидацию и верификацию каждого элемента системы распределенного реестра (рисунок 1).

Таким образом: информационные данные внедряются в сеть в целом, и они не могут быть непубличными.

Внешнее воздействие на принятие решения, т.е. изменить любое значение информации в системе распределенного реестра потребует невероятно огромной вычислительной мощности, чтобы изменить информацию всех элементов в сети.

Несмотря на то, что технология блокчейн имеет ряд неоспоримых преимуществперед другими технологиями, все еще остается нерешенным ряд вопросов.

Одноранговая децентрализованная сеть

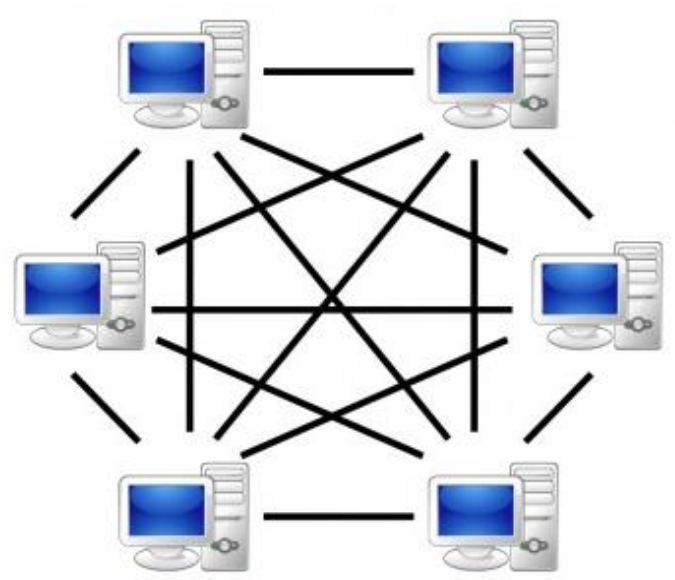

Puc. 1. Схема различия между стандартными и распределенными реестрами 


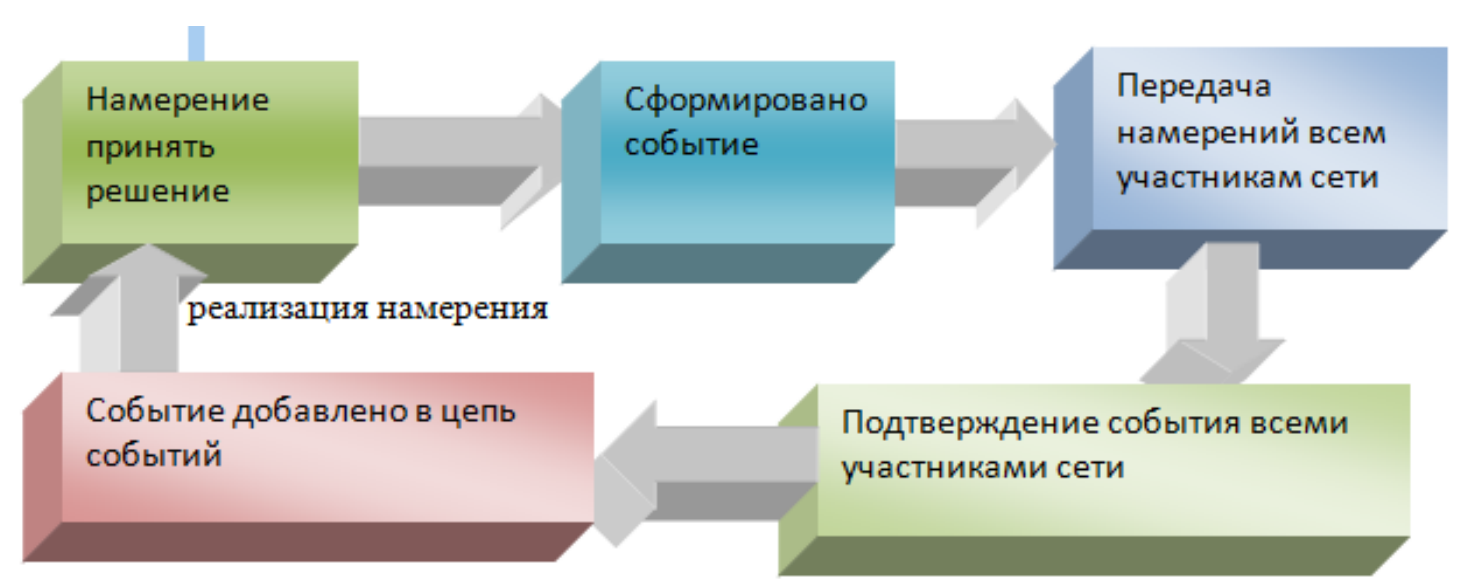

Рuc. 2. Процесс принятия решения при использовании систем распределенного реестра

\section{Заключение}

Блокчейн - основа интеллектуальной системы принятия объективных управленческих решений.

Возможности: для организации здравоохранения, где внедрена и сертифицирована система менеджмента качества возможно использовать СMК при формировании структуры распределенных баз данных, что сократит расходы на постановку задачи, декомпозицию процессов для создания регламентированных процедур; объективность принятия эффективных управленческих решений.

Риски: недостоверность информации при вводе в базы данных; воздействие третьих лиц; некомпетентность персонала; превышения плановых затрат из-за отсутствия практики внедрения и тестирования; отсутствие законодательной базы для функционирования и сертификации систем распределенного реестра.

\section{Библиографический список}

1. Путин В.В.: формирование цифровой экономики - вопрос нацбезопасности РФ.- ТАСС: [Электронный ресурс]. Режим доступа: http://tass.ru/ekonomika/4389411TACC: http://tass.ru/ekonomika/4389411

2. Гуськова М.Ф., Гуськов А.Ю., Стерликов П.Ф., Стерликов Ф.Ф. Цифровать экономику или информатизировать все области жизни// Экономические науки. 2017. № 152. С. 15-18; Гуськова М.Ф., Стерликов П.Ф., Стерликов Ф.Ф. Диалектика экономического прогресса // Экономические науки. 2006. № 7. С. 154.

3. Цыганов С.Н. Возможности применения технологии блокчейн в здравоохранении. //Перспективы развития науки и образования. Сб. науч. тр. по материалам XXI Международной научно-практической конференции. Под общей редакцией А.В. Туголукова. 2017. С. 123-126.

4. Интернет нового поколения: всё дело в блокчейне! [Электронный ресурс]. Режим доступа: http://bitnovosti. com/2015/05/23/internet_novogo_pokoleniya_vse_delo_v_blockchain/

5. Потемкина Н.С., Крутько В.Н. Концепция разработки распределенной базы данных «Здоровье России» В сборнике: Системный анализ в медицине (САM 2015) Материалы IX международной научной конференции. Под общей редакцией В.П. Колосова. 2015. С. 157-160. 